\title{
Research on Stability Analysis of Wind Power Generator Interconnection Grid System Based on Curve Method
}

\author{
Yang Zhao \\ Jinzhou Power Supply Branch \\ State Grid Liaoning Electric Power Supply Co. Ltd \\ Jinzhou, China \\ e-mail: zhanyangjz@163.com \\ Yu Li \\ Jinzhou Power Supply Branch \\ State Grid Liaoning Electric Power Supply Co. Ltd \\ Jinzhou, China \\ e-mail: liyujz@163.com
}

\author{
Yunzhi Li \\ Jinzhou Power Supply Branch \\ State Grid Liaoning Electric Power Supply Co. Ltd \\ Jinzhou, China \\ e-mail: liyunzhijz@163.com \\ Wenli Zhang \\ Jinzhou Power Supply Branch \\ State Grid Liaoning Electric Power Supply Co. Ltd \\ Jinzhou, China \\ e-mail: zhangwenlijz@163.com
}

\begin{abstract}
Wind power in China is currently one of the higher degrees of commercialization of renewable energy industries. 90s of the last century, wind power has made gratifying achievements, but also faces some problems and obstacles, if not properly resolved, will severely restrict the further development of wind power. This paper introduces interconnection grid technology, including wind power generator system of he constant speed constant frequency, synchronous generator direct driven wind turbine,doubly fed induction generator system and so on. Then it introduce $s$ its impact on aspects of the power quality, the power stability, and power shock. We use analysis method of the grid connected wind turbine stability to be analyzed from two aspects, and summarizes the relationship between increasing of active power of wind farm, wind power generator terminal voltage, and reactive power, the impact on the relationship between the fans and the network stability.Subsequent research has laid a theoretical foundation.
\end{abstract}

Keywords- renewable; restrict; quality; stability; impact

\section{INTRODUCTION}

The grid connected wind turbine can be divided into constant wind power generation system of speed and constant frequency, and wind power generation system of the variable speed constant frequency. The basic structure of wind power generation system of constant speed and constant frequency as shown in Fig .1, wind turbine of the natural wind, speed which is rising by the gear box drive asynchronous generator converting wind energy into electrical energy[1]. Generally used both at home and abroad are horizontal axis, direction, fixed pitch (or variable pitch wind turbine), its effective range of wind speed is about $3 \sim 30 \mathrm{~m} / \mathrm{s}$, the rated wind speed and general design for the $8 \sim 15 \mathrm{~m} / \mathrm{s}$, the rated wind speed is about 20 30 / $\mathrm{min}$.

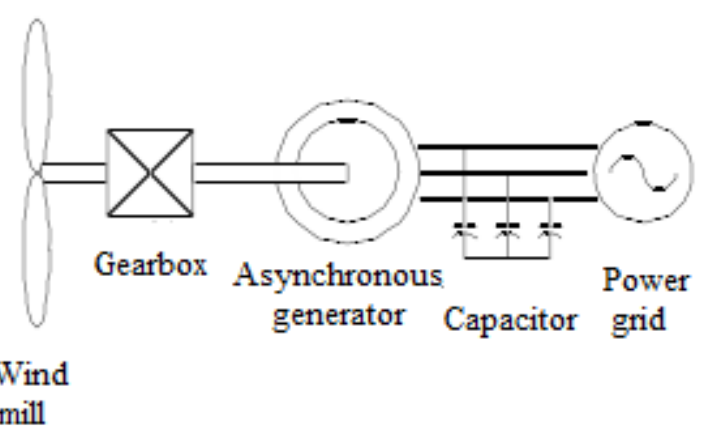

Figure 1. Wind power generator system of he constant speed constant frequency

Development of variable speed and constant frequency wind power generation system depends on the large capacity and mature power electronic technology, the structure and the operation can be divided into direct driven synchronous generator system and doubly fed induction generator system, the basic principle as shown in Fig .2 and 3 show [2]. In the wind turbine direct drive VSCF wind power generation system of synchronous generator in a wind machine, wind power machine directly connected with the generator, do not need increasing speed by gearbox, the output voltage of the generator frequency changes with the rotating speed, the AC - DC - AC or AC $\mathrm{AC}$ frequency converter and grid voltage, frequency constant in the grid side [3].

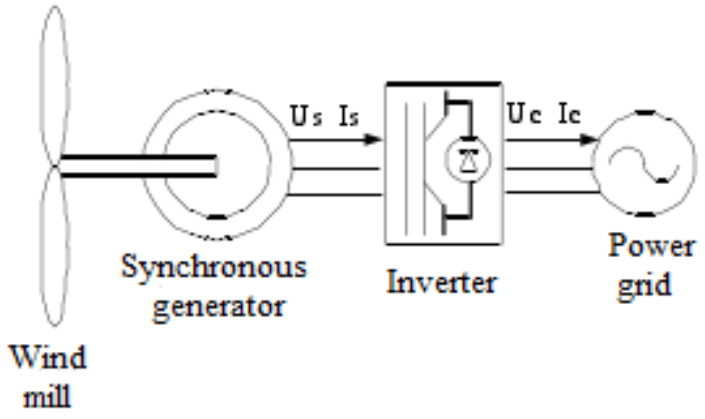

Figure 2. Synchronous generator direct driven wind turbine 
The basic structure of the doubly fed induction generator wind turbine include winding induction generator, inverter and control links, the stator winding is directly connected to the network, the rotor adopts threephase symmetric winding, after back-to-back bidirectional voltage source converters connected to the grid, and supply $\mathrm{AC}$ excitation to the generator, excitation frequency is the slip frequency generator [4].

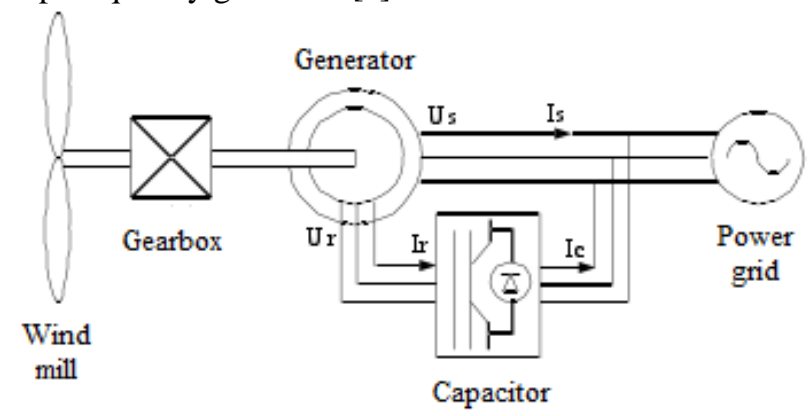

Figure 3. Doubly fed induction generator system

Variable speed constant frequency wind turbine achieve decoupling of generator speed and power grid frequency, reduce the interaction between wind power and grid, but its complex structure, high cost, difficult technology. The mainstream is still not wind power equipment [5]. With the development of power electronics technology, variable speed and constant frequency wind power generation technology will further mature. Especially the doubly fed induction generator, not only improve the performance of the wind turbine, but also greatly reduces the capacity of inverter, will become the main choice of wind power equipment in the future.

\section{TECHNICAL PROBLEMS}

Constant speed and constant frequency wind power generation system has the advantages of simple structure, low cost, strong overload capacity and high reliability, is currently the main wind power equipment. But in the constant speed and constant frequency wind power generation system, on the one hand, the wind turbine directly coupled with power characteristic of wind power which will directly affect the power grid, on the other hand, the power equipment for asynchronous generator, its operation needs no power supply support, increased the burden of wattles power grid, bring the current distribution more complex [6]. Therefore, grid connected operation will give the planning, design and operation of the system bringing many new problems which is different from the conventional energy generation, with the scale of wind power continues to expand, these problems will become more prominent. Research and experience of domestic and foreign scholars and engineering technical staff that, wind farm grid will mainly face the following technical problems.

\section{A. The impact of power quality}

By variation of wind speed, turbulence and wind turbine wake effect caused turbulence will cause the frequency of the fluctuation of wind power and wind power unit commitment; tower shielding effect of the wind machine make output power of the wind turbine exist a periodic. The change of power will make the grid frequency fluctuation in a certain range, affecting the normal work of power grid frequency sensitive load [7].

Changing in the fluctuation of wind power is bound to cause voltage, mainly as follows: the voltage fluctuations, voltage flicker, voltage sag and periodic voltage pulsation.

In addition, if electronic control device of the wind turbine power designed improperly, it will inject harmonics into grid, cause voltage waveform distortion unacceptable, and may lead to potential problems by the resonance.

\section{B. Effect on stability}

On the one hand, wind power is usually access to the end of the grid, changing the character of the distribution network power flow in one direction, so that the flow direction and distribution change, which planning and design of the original power grid is not considered in advance [8]. Therefore, with the wind power into the power increasing, the voltage and power in the local power grid wind farm will be beyond the safe range, which may lead to voltage collapse.

In addition, because of the asynchronous generator, variable speed and constant frequency wind power system inject power to the grid; at the same time need absorb a lot of no reactive power from the grid. Therefore, in order to remedy wattles power compensation wind farms, each wind turbine is equipped with power factor correction devise, parallel capacitor switching is the most commonly used. The size and the access point of wattles power compensation of the capacitor voltage is proportional to the square, when voltage level of the system is low, no amount of reactive power compensation capacitors in parallel decline rapidly, leading to increased demand for wind farms without power grid, further deteriorate voltage level, which can cause voltage collapse. In addition, because asynchronous generator power has recovery characteristics, when the power grid fault occurs, if the fault is not timely cut off, it will easily lead to transient voltage instability.

On the other hand, with the growing size of wind farms, the wind field in the whole system increased, the impact effect of wind power output power instability on the grid will continue to increase, on the stability of the system is even more significant. In severe cases, it will cause the system to lose stability, collapse of the entire system.

\section{The impact of power Grid on interconnection Grid:}

When asynchronous motor as a generator is running, which has no independent excitation device, the generator before grid connected has no voltage, so the grid must be accompanied by a transition process, through the 5 to 6 times of the rated current, generally after a few hundred milliseconds which transfer to the steady state. The impact of asynchronous generator current relate to the network voltage ,the grid transient reactance and slip on. If the slip is greater, AC transient decay time will be longer, the impact of grid connected current effective value is greater. When the wind turbine is connected with the power grid, have not much impact current the closing moments of the operation of generator and power system security. But for small capacity power grid, grid connected wind farm 
moment will cause voltage drop, thus affecting the normal operation of the other electrical equipment in the same grid, and even affect the stability and security of the whole power grid.

\section{Impact on the protection device:}

In order to reduce the frequent wind turbine switching to contactor damage, during the wind during wind turbine are connected to power grid, when the wind speed changes in the starting wind speed near, allowing the unit shortterm operation of electric motors, so power flow of the tie lines between wind farm and power grid is sometimes twoway. Therefore, relay protection configuration and setting should take full account of this mode of operation of wind farm [9].

Asynchronous generator cannot provide fault currents for short distance three-phase short-circuit fault, short circuit current in unbalanced faults are also very limited. Therefore the technical difficulties of technical protection of wind farm is how to detect the fault according to the fault limited current, so that the protection device for accurate and rapid act. On the other hand, although the fault current supplied by wind power is very limited, but also may affect the correct operation of the existing distribution network protection device, which in the initial distribution network protection configuration and setting are not taken into account.

\section{E. The influence of other aspects :}

In addition to the above effects, distribution network reliability and economic problem caused by wind power grid operation has caused the attention of scholars and engineering technicians.

For grid connected wind farm on the impact of the current understanding of power grid, the current understanding of the comparatively mature, and has adopted appropriate measures to solve. In commonly it used in soft start two-way thruster control (Soft-Start) device. The soft start device principle shown in Fig .3Fig .4. When the wind turbine generator to the synchronization speed, circuit breaker closing end of generator, the generator through a bidirectional thruster and grid connected current feedback, the conduction angle of the bidirectional thruster control, the bidirectional thruster trigger angle is to gradually open, grid process ends later, the bidirectional thruster short circuit. By using soft starting, to limit the impact of current grid connected wind farm is within 1.2 1.5 times rated current, get a smooth integration process.

In addition, through artificial intervention can make that the wind turbine is not at the same time start, can further limit the impact on the power grid wind turbine startup.

In protection configuration and setting of the wind farm, the usual

Method is to configure and set according to the terminal substation. It mainly rely on the protection of distribution network to remove network fault, then the ways of the islanding protection and low voltage protection measures cut off wind turbines, during the fault breaking wind farm with the system. When the fault is cleared, the wind farm grid connected control automatically again.

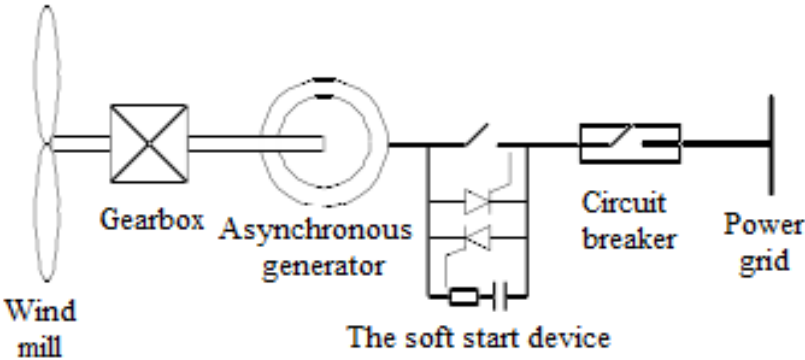

Figure 4. The soft starting circuit principle diagram

From operation experience of the countries of the world wind farm, The large-scale wind power grid connect power field to bring the main question, one is that the fluctuation and randomness of wind cause wind farm output with time-varying wind farm output, on the other hand is weak system stability and power quality problems. The stability and power quality, impact of wind power on the voltage stability of the system and the quality are the more prominent. The main reason is the limitation of resource distribution, wind farm are generally distributed in the coastal and border areas, the access network is mostly distribution area load properties, the network structure is single, the local power supply (especially power supply with fast adjustment ability) is relatively small, the electrical connection between the relatively is weak, the ability to fight against wind power disturbance is relatively low, the fluctuation of wind power will cause significant changes in the local power grid voltage, the other asynchronous generator dynamic and shunt capacitors, the voltage stability of the system become more threat. In our country, this problem is particularly prominent, but it has not caused enough attention of the relevant units and departments, so there are more problems.

\section{STABILITY ANALYSIS METHOD OF INTERCONNECTION GRID WITH WIND MACHINE}

Voltage stability of power system refers to the system in a given state, the load node maintain the ability of original level of voltage after a disturbance. According to the time domain range and disturbances, voltage stability is divided into small disturbance voltage stability, transient voltage stability and long-term voltage stability. Small disturbance voltage stability refers to the system after being suffered any small disturbance, load voltage own ability to recovery to undisturbed voltage level, Transient voltage stability refers to system after being disturbed, ability to load nodes maintain ability of voltage levels, Long term voltage stability refers to the system subjected to large disturbances, load increases or the transmission power increase, in minute range, capability of load node to maintain the voltage level.

The study of voltage stability is still in the immature stage, there is a lack of analysis method of a complete set of theory and system, even without a definition of voltage stability recognized and classification method. As for the proposed method of the mechanism, mathematical model of voltage stability analysis, discriminate, stability index and countermeasures and so on, there are many differences. This paper only considers voltage stability of interconnection Grid of wind farm, that is voltage on the 
power from the variation of wind caused lower or higher, its mechanism involves only associated with the wind element, simplify considered characteristic of other electrical components in the system [10].

The voltage stability problem of Grid farm connected wind farm belong to the small signal voltage stability analysis, usually as a static problem, main research means is tidal current simulation.

Application of P-V curve is convenient for analyzing voltage stability and studying radiation type transmission system from the concept. When wind farms operate in the critical operating conditions, small disturbance of wind speed of wind farm will lead to voltage collapse, so, for the calculation of Wind Farm about small disturbance voltage stability limit point is the main study of operation stability problems of grid connected wind farm, it has important practical significance for the safe operation of wind farm.

According to the differentia of the principle and characteristics, the solving method for small disturbance voltage stability of power system limit can be divided into three categories: direct method, optimization method and step by step method. The direct method uses the iterative calculation to directly determine the voltage stability limit, its main advantage is the simple algorithm, disadvantage is that the selection of iterative initial value is the lack of systematic and effective method, and the initial value of iteration divergence or convergence selection will lead to no physical meaning solution properly, and this method does not consider the condition of generator reactive limits. Optimization method is that the solution of the voltage stability limit is transformed into a nonlinear optimization problem with constraint; its advantage is easy to consider a variety of constraints, but the large amount of calculation. Point by point method is to start from the current system steady-state operation point, point by point for finding out the change process of the trajectory, and generally with the inflection point of the P-V curve as the limit state voltage stability, it includes the repeated power flow method and continuous method two, inflection point repeated power flow method is through continuous load flow equations are solved to get $\mathrm{P}-\mathrm{V}$ the curve, the continuation method is a method of trajectory solution of nonlinear algebraic equations.

In calculating the wind electric field P-V curve, in addition to the system equilibrium point, regardless of system changes of other power plant of active power and the bamboo point load, which $\mathrm{P}$ represent the increase of active power of wind farm, $\mathrm{V}$ said wind power generator terminal voltage.

\section{A. $\quad V$-Q curve method}

Through a series of power flow calculation, we may obtain V-Q the curve. It says the relationship between the key generatrix voltage and reactive power. If the generatrix is equipped with a virtual synchronous condenser, then in power flow calculation the generatrix is not affected by the reactive power limits, as PV the node. So, in power flow calculation, voltage of the synchronous condenser is arranged as a series of values, then the point of no power output corresponding to the voltage value can obtain V-Q curve. This voltage conduct independent variables and the abscissa, reactive power conduct ordinate.

Voltage stability of grid connected wind farms, not only related with the characteristics of wind turbines, but also has the close relation with the system voltage characteristics. Reactive power and system voltage characteristics are closely linked; the aims of calculated V$\mathrm{Q}$ curve the robustness of test power system by increasing reactive power of the test nodes.

The test node for bus high side wind power booster substation, voltage range from 0.9 to $1.1 \mathrm{Pu}$. When the voltage exceeds the range, relay protection of wind turbine will act.

\section{CONCLUSION}

We use fans and networks stability analysis method to be analyzed from two aspects and summarize the relationship between increasing of active power of wind farm, wind power generator terminal voltage, and reactive power, the impact on the relationship between the fans and the network stability. Subsequent research has laid a theoretical foundation

\section{REFERENCES}

[1] H.Z.Dai,M.Z.Chen,W.S.Wang, andX.R.Wang, "Developmen t of China's wind power and related technical services," Chi.Ele.Pow, vol.1 .pp.1-4.May 2005

[2] S.W.Mohod and M.V. Aware, "Battery Energy Storage to Strengthen the Wind Generator in Integrated Power System", Jou. Elec. Sci. Tech, vol. 9, pp. 23-30,July,2009

[3] D.S. He, and Y.Q.Liu, "Grid wind power system studies , " High .Vol.Tech, vol.1, pp. 142-146,May 2008.

[4] K.Li, "Grid-connected wind power generation system Summary, " Micro-motor, vol.6, pp. 83-86,June 2010

[5] Y.N.Chi, Q.Y.Li, and Y.Li, "Other large-scale wind power and grid power system operation and stability problems caused," Elec.Equ, vol.8 pp. 16-19,October,2008

[6] H.L.Guan, H.X.Zhao,Y.N.Chi, and and W.S.Wang, "Other power systems for grid-connected wind turbines that require low voltage withstand capability, " Grid technology, vol.7, pp.78-82,June 2007

[7] P.YangL.L.Sun,and N.Wu, "Grid wind power system voltage stability of the status," Comm.Ene.Tech, vol.7, pp.16-20,May 2012

[8] L.Chen, X.Z.Xia, and M.F.Zhong, "Large wind turbine technology trends,"Ren.Ene,vol.17, pp.116-120,May 2003

[9] B.Zhang and J.Zeng, " Battery energy storage systems to improve grid power quality and stability of grid power , " Grid. Tech, vol.34, pp.21-26,May 2013

[10] J.H.Yu and H.Zhou, "Present Situation and Prospects of China's wind power development, " Wind. Turb.Techn, vol.39, pp.1318,July 2009 